\title{
Modifier genetics in neuropsychiatric disease: challenges and opportunities
}

\author{
Elizabeth K Ruzzo', Andrea L Pappas² and David B Goldstein ${ }^{1 *}$
}

\section{Abstract \\ A new study focuses attention on multigenic interactions influencing the risk of autism spectrum disorders.}

In recent years, efforts to uncover the etiology of neuropsychiatric disorders have revealed a number of rare copy number variants (CNVs) that have variable expressivity within and across clinically distinct disorders. For example, CNVs in 1q21.1 are associated with a number of phenotypes, including intellectual disability (ID), microcephaly, schizophrenia and autism spectrum disorder (ASD) [1]. Such observations have brought the potential role of modifier mutations to the forefront of neuropsychiatric disease genetics. A recent study by Leblond et al. [2] published in PLoS Genetics has investigated the possible impact of genetic variation at other loci in patients carrying de novo deletions in an established autism gene.

Given the complexity of neuropsychiatric disease, the increasing support for major risk factors interacting strongly with one another and with the genetic background should come as no surprise. Work in model organisms has revealed rampant genetic interactions. For example, a single mutation in any of the approximately 1,000 essential genes of yeast induces lethality, but it is estimated that there are 200 times as many digenic combinations resulting in synthetic lethality [3]. In contrast, we have only a handful of examples in human diseases where multiple hits are required for manifestation of a disease. Unfortunately, identification of genetic interactions in humans has proved difficult. Even in Mendelian diseases where the genetic architecture is simplified by low locus heterogeneity, progress has been slow, with only a few robust examples, including sickle cell anemia and cystic fibrosis [4]. In both

\footnotetext{
*Correspondence: d.goldstein@dm.duke.edu

'Center for Human Genome Variation, Duke University School of Medicine, Durham, North Carolina, 27708, USA
}

cases, the phenotypic expression is modified by variants outside of the disease-causing gene. In cystic fibrosis, as in many other diseases, different mutations within the diseasecausing gene $C F T R$ can also result in differences in disease severity [4], making it harder to identify interactions.

A new study by Albers et al. [5] published in Nature Genetics investigates the genetic interactions responsible for thrombocytopenia with absent radii syndrome. By focusing on patients harboring a previously associated microdeletion in 1q21.1, they identified two different lowfrequency variants in the regulatory region of $R B M 8 A$. The combination of either variant with the original microdeletion is sufficient to cause this disorder. Subsequently, patients lacking the microdeletion were found to carry novel null mutations in $R B M 8 A$, thus resolving the responsible gene within the 1q21.1 region. This compound inheritance mechanism explained 53 of 55 cases $\left(P<5 \times 10^{-228}\right)$ and provides a simplified model that can be applied in studies of neuropsychiatric disorders. However, given the low frequency of risk alleles and the extreme genetic heterogeneity of neuropsychiatric disorders, identifying well-powered cohorts of genetically homogeneous samples will be no small task.

Common complex diseases represent a particular challenge for studying modifier genetics. Perhaps the most fundamental constraint is that the high locus heterogeneity complicates identification of patients with similar 'primary' mutations in order to ask how these interact with modifiers. So far, such efforts have been modest. In the case of heterozygous microdeletions, one possibility is that variable expressivity is due to newly hemizygous deleterious mutations in distinct genes on the remaining chromosome. This possibility has been tested in only a few studies to date $[1,6]$, with no clear evidence of genetic modifiers on the intact chromosome. Admittedly, the small sample sizes in these studies mean that it is difficult to rule out this possibility even for the deletion regions that have been tested. Other studies have looked elsewhere in the genome for evidence of genetic interactions. Girirajan et al. [7] performed a genome-wide scan for CNVs in ID patients carrying the 16p12.1 microdeletion and identified a nonspecific enrichment of large CNVs that correlated with a more severe clinical phenotype. Perhaps the presence of 
one causal CNV more readily allows the presence of others compared with controls. It remains unclear whether these observations are reflective of a primary driver with secondary modifiers or if some combination of multiple hits is necessary for manifestation of the phenotype.

ASD may present one of the clearest cases for strong genetic interactions. The heritability of ASD is well established, and some twin studies indicate that concordance rates for monozygotic twins (70\% to $90 \%)$ are much higher than for dizygotic twins $(0 \%$ to $10 \%)$ [8]. One explanation for this would be that several interacting risk factors are necessary to confer a higher risk for ASD. Preliminary work supports the idea that multiple risk factors are present in patients with ASD [9]; specifically, that rare $\mathrm{CNVs}$ are enriched (approximately 1.2-fold) in ASD cases compared with controls and particularly enriched (approximately 1.7-fold) at known ASD/ID loci. The challenge imposed by locus heterogeneity is exemplified by the fact that the genetic cause of ASD is now thought to be known in $10 \%$ to $20 \%$ of cases, and yet the variants explaining the highest proportion of cases still individually explain no more than $1 \%$ to $2 \%$ [8]. This is further complicated by the phenotypic spectrum seen in patients with ASD who carry mutations in the same gene, which is also consistent with the analysis of Shank3 mutant mice. Unexpectedly, Shank3 mutant strains with four unique deletions (for example, deleting exons 4 to 9 removes the ANK domain [10]) show phenotypic variability, which may be reflective of the genotype-phenotype variability seen in patients with SHANK3 mutations.

The study by Leblond et al. [2] investigates the possible impact of genetic variation at other loci by examining the CNVs of three patients carrying de novo deletions in an established autism gene, SHANK2. They found that all three patients had CNVs within the $15 \mathrm{q} 11-\mathrm{q} 13$ region: two causing a duplication of CHRNA7 (15q13.3) and the third causing a deletion of NIPA1, NIPA2, CYFIP1 and TUBGCP5 (15q11.2). In their case-control cohort, none of the CNVs showed significant enrichment in patients with ASD. In contrast to neuropsychiatric-disease-associated deletions encompassing this gene, the CHRNA7 duplication is of unknown clinical significance and was seen in about $1 \%$ of patients with ASD and about $0.6 \%$ of controls. These results provide a tantalizing suggestion that nicotinic cholinergic receptors may act in a pathway that is shared with $S H A N K 2$ to confer risk of ASD. If confirmed, this observation would provide an important indicator of the precise pathways that underlie risk. But this work also clearly illustrates the challenges involved in ASD modifier studies. It is worth noting that $15 q 11-q 13$ is a hotspot for structural rearrangements, meaning that the region often carries CNVs, even in controls, and also that it is difficult to accurately call CNVs in this region. As an illustration, we observed in our own unpublished raw data (not experimentally validated) that $4.56 \%$ of our healthy controls $(59 / 1,295)$ harbor a CNV in this region that is large enough to be called by PennCNV $(>2 \mathrm{~kb})$. Even the CHRNA7 duplication observed in this paper is identified in $1.16 \%$ of our control cohort $(15 / 1,295)$, and the reciprocal deletion of CHRNA7 is called in $1 \%$ of controls $(13 / 1,295)$.

This study also illustrates the challenge imposed by locus heterogeneity. Analyzing only three patients with de novo SHANK2 deletions hinders identification of modifiers with statistical certainty. Thus, in an effort to identify additional patients with causal SHANK2 mutations, Leblond et al. investigated the likelihood of pathogenicity for candidate variants seen in patients with ASD by overexpressing them in neuronal cultures. Overexpression of SHANK2 variants seen in only cases, only controls or both cases and controls revealed an interesting pattern among the 16 tested variants. Four variants significantly reduced synaptic density, and three of these variants were seen only in cases, while the fourth was seen in both cases and controls. Importantly, none of the control-only variants had an impact on synaptic density. This functional work demonstrates the potential utility of in vitro or in vivo models to gauge pathogenicity among a set of candidate variants, but also shows the difficulty of confident assignment of pathogenicity based on such analyses.

Developing well-powered modifier studies for ASD will be a very significant challenge. Leblond et al. [2] took a key first step by jointly analyzing three patients with de novo SHANK2 deletions, and this raises the captivating possibility that modifiers within $15 \mathrm{q} 11-\mathrm{q} 13$ interact with SHANK2 mutations to confer ASD. It is unclear whether identifying and considering other presumably causal SHANK2 mutations would strengthen the initial observation of the role of CNVs within 15q11-q13, or if the inability to securely identify pathogenic variants would dilute this signal. Either way, to obtain the statistical evidence needed to prove such associations, large wellphenotyped and homogeneous datasets must be compiled, highlighting the need for collaborative efforts among researchers.

We are in the earliest days of identifying genes contributing to ASD. However, already it seems likely that synaptic structure and function will play a central role. On a broader level, identification of multiple genetic aberrations in patients, or unaffected individuals, may reveal important combinatorial effects on phenotypic variability and novel underlying biological interactions.

Making effective clinical use of genetic risk factors depends critically on understanding the basis of pathogenicity in individual genomes. Only through such understanding will it be possible to organize all the different rare genetic risk factors, which many expect to underlie common diseases, into a discrete number of alternative disease-associated pathways. Once such mappings are 
established between collections of genetic risk factors and the pathways they affect, it will become possible to target those pathways in drug development efforts and tailor treatment for patients having different pathways perturbed. As challenging as they may be, one critical direction for relating genetic risk factors to such pathways is through modifier genetic studies such as the one reported by Leblond et al. [2].

\section{Abbreviations}

ASD, autism spectrum disorder; CNV, copy number variant; ID, intellectual disability.

\section{Competing interests}

The authors declare that they have no competing interests.

\section{Acknowledgements}

We would like to thank YH Jiang, G Gibson, S Petrovski, EL Heinzen, AC Need, ET Cirulli, K Pelak and AJ Towers for their thoughtful reviews of this manuscript.

\section{Author details}

'Center for Human Genome Variation, Duke University School of Medicine, Durham, North Carolina, 27708, USA. ²Department of Neurobiology, Duke University, Durham, North Carolina, 27708, USA

Published: 28 March 2012

\section{References}

1. Mefford HC, Sharp AJ, Baker C, Itsara A, Jiang Z, Buysse K, Huang S, Maloney VK, Crolla JA, Baralle D, Collins A, Mercer C, Norga K, de Ravel T, Devriendt K, Bongers EMHF, de Leeuw N, Reardon W, Gimelli S, Bena F, Hennekam RC, Male A, Gaunt L, Clayton-Smith J, Simonic I, Park SM, Mehta SG, Nik-Zainal S, Woods CG, Firth HV, et al:: Recurrent rearrangements of chromosome 1q21.1 and variable pediatric phenotypes. N Engl J Med 2008, 359:1685-1699.

2. Leblond CS, Heinrich J, Delorme R, Proepper C, Betancur C, Huguet G, Konyukh M, Chaste P, Ey E, Rastam M, Anckarsäter H, Nygren G, Gillberg IC, Melke J, Toro R, Regnault B, Fauchereau F, Mercati O, Lemière N, Skuse D, Poot M, Holt R, Monaco AP, Järvelä I, Kantojärvi K, Vanhala R, Curran S, Collier DA, Bolton P, Chiocchetti A, et al:: Genetic and functional analyses of SHANK2 mutations suggest a multiple hit model of autism spectrum disorders. PLoS Genet 2012, 8:e1002521.

3. Boone C, Bussey $H$, Andrews BJ: Exploring genetic interactions and networks with yeast. Nat Rev Genet 2007, 8:437-449.

4. Antonarakis SE, Beckmann JS: Mendelian disorders deserve more attention. Nat Rev Genet 2006, 7:277-282.
5. Albers CA, Paul DS, Schulze H, Freson K, Stephens JC, Smethurst PA, Jolley JD, Cvejic A, Kostadima M, Bertone P, Breuning MH, Debili N, Deloukas P, Favier R, Fiedler J, Hobbs CM, Huang N, Hurles ME, Kiddle G, Krapels I, Nurden P, Ruivenkamp CAL, Sambrook JG, Smith K, Stemple DL, Strauss G, Thys C, van Geet C, Newbury-Ecob R, Ouwehand WH, et al:: Compound inheritance of a low-frequency regulatory SNP and a rare null mutation in exon-junction complex subunit RBM8A causes TAR syndrome. Nat Genet 2012. doi: 10.1038/ng.1083.

6. Heinzen EL, Radtke RA, Urban TJ, Cavalleri GL, Depondt C, Need AC, Walley NM, Nicoletti P, Ge D, Catarino CB, Duncan JS, Kasperaviciutedot D, Tate SK, Caboclo LO, Sander JW, Clayton L, Linney KN, Shianna KV, Gumbs CE, Smith J, Cronin KD, Maia JM, Doherty CP, Pandolfo M, Leppert D, Middleton LT, Gibson RA, Johnson MR, Matthews PM, Hosford D, et al:: Rare deletions at 16p13.11 predispose to a diverse spectrum of sporadic epilepsy syndromes. Am J Hum Genet 2010, 86:707-718.

7. Girirajan S, Rosenfeld JA, Cooper GM, Antonacci F, Siswara P, Itsara A, Vives L, Walsh T, McCarthy SE, Baker C, Mefford HC, Kidd JM, Browning SR, Browning BL, Dickel DE, Levy DL, Ballif BC, Platky K, Farber DM, Gowans GC, Wetherbee JJ, Asamoah A, Weaver DD, Mark PR, Dickerson J, Garg BP, Ellingwood SA, Smith R, Banks VC, Smith W, et al:: A recurrent 16p12.1 microdeletion supports a two-hit model for severe developmental delay. Nat Genet 2010 42:203-209.

8. Abrahams BS, Geschwind DH: Advances in autism genetics: on the threshold of a new neurobiology. Nat Rev Genet 2008, 9:341-355.

9. Pinto D, Pagnamenta AT, Klei L, Anney R, Merico D, Regan R, Conroy J, Magalhaes TR, Correia C, Abrahams BS, Almeida J, Bacchelli E, Bader GD, Bailey AJ, Baird G, Battaglia A, Berney T, Bolshakova N, Bölte S, Bolton PF, Bourgeron T, Brennan S, Brian J, Bryson SE, Carson AR, Casallo G, Casey J, Chung BHY, Cochrane L, Corsello C, et al:: Functional impact of global rare copy number variation in autism spectrum disorders. Nature 2010, 466:368-372.

10. Wang X, McCoy PA, Rodriguiz RM, Pan Y, Je HS, Roberts AC, Kim CJ, Berrios J, Colvin JS, Bousquet-Moore D, Lorenzo I, Wu G, Weinberg RJ, Ehlers MD, Philpot BD, Beaudet AL, Wetsel WC, Jiang YH: Synaptic dysfunction and abnormal behaviors in mice lacking major isoforms of Shank3. Hum Mol Genet 2011, 20:3093-3108.

doi:10.1186/gb-2012-13-3-150

Cite this article as: Ruzzo EK, et al:: Modifier genetics in neuropsychiatric disease: challenges and opportunities. Genome Biology 2012, 13:150. 